\title{
Demonstrações Alternativas e Re-Demonstrações na Produção e no Ensino de Matemática
}

\author{
Alternative Demonstrations and Re-Demonstrations in the Production and Teaching of \\ Mathematics
}

\author{
Rosemeire de Fatima Batistela*a; Maria Aparecida Viggiani Bicudo ${ }^{\mathrm{b}}$; Henrique Lazaric \\ ${ }^{a}$ Universidade Estadual de Feira de Santana, Departamento de Ciências Exatas. BA, Brasil. \\ 'Universidade Estadual Paulista, Programa de Pós-Graduação Stricto Sensu em Educação Matemática. SP, Brasil. \\ ${ }^{c}$ Universidade Estadual Paulista, Departamento de Matemática. SP, Brasil. \\ *E-mail: rosebatistela@gmail.com
}

\begin{abstract}
Resumo
Neste estudo tratamos o tema demonstrações matemáticas com foco na atividade de demonstrar novamente resultados que já foram comprovados e buscamos entender as razões que impelem a prática matemática de elaboração de demonstrações alternativas. Expomos e justificamos nosso entendimento de que re-demonstrar e efetuar demonstrações alternativas é um modo de produzir matemática. Entendemos que na prática pedagógica ao ensinar matemática, a atividade de re-demonstrar e de efetuar demonstrações alternativas são importantes e destacamos a relevância de serem trabalhadas no ensino visando a aprendizagem dos professorandos em cursos de formação de professores de matemática.

Palavras-chave: Demonstrações Matemáticas. Demonstrações Alternativas. Ensino Superior.
\end{abstract}

\begin{abstract}
In this study, one deals with the topic of mathematical demonstrations with a focus on the activity of demonstrating results that have already been proven and one seek to understand the reasons that impel the mathematical practice of preparing alternative demonstrations. One exposes and justifies our understanding that re-demonstrating and performing alternative demonstrations is a manner of producing mathematics. One understands that in the pedagogical practice when teaching mathematics, the activity of re-demonstrating and making alternative demonstrations are important and one highlights the relevance of this content to be worked on formation teacher courses aiming the learning of the undergraduate students in mathematics.
\end{abstract}

Keywords: Mathematical Demonstrations. Alternative Demonstrations. University Education.

\section{Introdução}

Neste texto tratamos o tema demonstrações matemáticas com foco na atividade de demonstrar novamente resultados que já foram comprovados e buscamos entender as razões que impelem a prática matemática de elaboração de demonstrações alternativas. Expomos nossa visão de que demonstrar novamente faz parte da atividade matemática.

Partimos do entendimento que o trabalho de elaborar redemonstrações em cursos realizados no Ensino Superior, que têm por meta a formação inicial de matemáticos ou professores de matemática, vai ao encontro da prática de matemáticos profissionais. Entendemos que, ainda que não seja o trabalho de um matemático profissional, essa atividade privilegia a lógica da produção em matemática sendo importante para o desenvolvimento da formação do professor e para a confiança matemática do professor ${ }^{1}$.

Demonstrar ou provar em matemática não é uma atividade que se processa mecanicamente, ou seja, não há uma sequência de passos que possam ser dados em etapas por uma máquina em finitas operações que realize essa atividade. O trabalho do matemático, quando é exposto na apresentação de uma teoria ou na demonstração de algum teorema, pode dar a impressão de que o processo desenvolvido se resuma em definir objetos e

1 Compartilhamos do entendimento apresentado em Viola dos Santos e Lins (2016) que expõem que a confiança é um dos três pilares que sustentam a formação matemática sólida de um professor de matemática, sendo que ela, a confiança, advém do envolvimento da pessoa com situações e problemas matemáticos enfrentando-os conforme a confiança que já detém e vai resolvendo e estando aberto e disposto aos enfrentamentos, ao invés de fugir de situações que envolvam matemática. Os outros dois pilares, segundo esses autores são maturidade matemática e repertório.

2 Edith Stein tratou de desenvolver as ideias de Husserl a respeito de como os seres humanos vivem juntos. Ales Bello (2006) apresenta que sendo humanos sempre vivemos junto com os outros e expõe as formas de organização de associações humanas. Essas formas são muito importantes para compreender o papel de cada pessoa no seu contexto associativo. Então, podem-se perguntar quais formas associativas favorecem o posicionamento de cada pessoa e que tipo de associação promove o movimento de cada um. A dimensão interpessoal é tão importante que toda a nossa educação depende da interpessoalidade em que estamos inseridos. Estes modos de associações podem ser: Massa, Sociedade, Comunidade ou Estado. Dentre esses modos possíveis ela destaca que a comunidade é a maneira mais importante do viver junto, pois ela é a que mais pode contribuir para o desenvolvimento de cada membro. Para que ocorra a contribuição da comunidade para os membros, cada membro precisa conviver com os outros. Nessa associação, os membros dão importância às três dimensões que constituem o ser humano, quais sejam, corpo, psique e espírito. Segundo essa autora o que caracteriza uma comunidade é sempre a unidade espiritual, cultural e da vontade coletiva. 
derivar resultados por meio de regras lógicas. Entretanto, essa tarefa requer intuições claras e, ao mesmo tempo, ajustes de ideias aos padrões aceitos pelo grupo de pesquisa do próprio autor e pela comunidade ${ }^{2}$ matemática.

Ao dizemos comunidade matemática estamos nos referindo àqueles que convivem em grupos de pesquisa, que se empenham em se familiarizarem com os instrumentos que compartilham e com os quais trabalham para convencer a si próprios e aos demais quanto à validade da demonstração. Isso envolve compartilhamento de regras, de conceitos e de rigor matemático.

Entendendo que uma demonstração é a prova da existência matemática de algo, afirmamos que a prática de elaborar demonstrações alternativas é também um exercício de apresentação de ideias e argumentos que visa convencer o público ao qual se destina. Isso pode ocorrer em contextos e com atores diversos, dentre os quais destacamos: em escolas para crianças e adolescentes quando os professores ensinam aos estudantes as provas provenientes de resultados; em cursos de graduação em matemática, quando estudantes trabalham juntos elaborando demonstrações, esforçandose para familiarizarem-se com ferramental das teorias; nas apresentações de trabalhos acadêmicos apresentados em eventos ou para divulgação em revistas, quando apresentam resultados novos ou reelaborados com roupagens para públicos especializados e ou não especializados.

Expondo seu pensar a respeito das ações de intuir versus formalizar, Walter Carnielli em 2013, na entrevista ${ }^{3}$ intitulada Problemão disfarçado de probleminha, conta sobre como chegou à prova de determinado teorema e se expressa nas seguintes palavras, "Passa-se um bom tempo entre ter a ideia e transformá-la em material de verdade" Carnielli (2013).

Destaca-se na passagem acima que a ideia não é suficiente, pois em Matemática somente se considera a expressão dessa ideia, respeitando-se o conceito de rigor vigente à época e aceito pela comunidade científico-acadêmica.

O conceito atual de rigor, no âmbito da ciência Matemática da civilização ocidental, diz de aceitar um resultado se, e somente se, ele for obtido pelas regras da lógica, entendida como a base das teorias formais da Matemática. Assim, para que uma ideia seja material de verdade ela deve existir e ser expressa nos moldes estabelecidos pela comunidade matemática. O conhecimento do ferramental matemático e a adequação entre esse conhecimento e a intuição de como a ideia pode ser expressa são imprescindíveis na articulação textual argumentativa que objetiva revelar o resultado no universo da Matemática.

Isso sinaliza que nem sempre o pensamento dedutivo prevalece no trabalho do matemático, pois ele, muitas vezes, visualiza de modo claro o dito no enunciado de um teorema e não sabe imediatamente como articulá-lo e expôlo matematicamente. No movimento de constituição do conhecimento ${ }^{4}$ que enlaça as vivências do sujeito cognoscente, as intuições e evidências encadeadas na ação de pensar, há um esforço para articulá-las tendo em vista delinear o objeto matemático e buscas para expressá-lo matematicamente, ou seja, de acordo com a própria linguagem matemática e sua lógica. Essas atividades estão presentes na articulação das compreensões realizadas pelo sujeito no âmbito da teoria, reunindo os sentidos e significados que envolvem e revelam os aspectos mais abrangentes.

Garnica (2002) cita Klein (1970) a respeito de tomar o método dedutivo como modelo pedagógico explicita. Ele traz a seguinte passagem: "a Matemática é uma atividade cujo primado é a atividade criativa, e pede por imaginação, intuição geométrica, experimentação, adivinhação judiciosa, tentativa e erro, uso de analogias das mais variadas, enganos e trapalhadas". Assim sendo, mesmo quando um matemático vê na evidência a solução da prova e está convencido de que seu resultado é correto, há muito trabalho a ser realizado para demonstrar aquilo que vê. Entendemos que essa atividade tem uma correspondência com o trabalho desencadeado junto aos estudantes. Quando um teorema é exposto, solicitandose que com ele trabalhem, é preciso que eles se emprenhem no movimento de compreender a mensagem do enunciado, os passos seguidos na demonstração, os pressupostos matemáticos que embasam a problemática do teorema e as ferramentas disponíveis para a articulação dos argumentos. É um movimento complexo em busca do ver claro e de se convencer, do ponto de vista do raciocínio lógico, a respeito da veracidade do resultado. Entendemos que esse é o próprio movimento de constituição e de produção e a compreensão e, portanto, também da produção do conhecimento matemático.

\section{Das Demonstrações Alternativas}

A noção do que constitui uma prova em uma teoria

\footnotetext{
3 Acesso em: https:/www.cocen.unicamp.br/noticias/id/63/problemao-disfarcado-de-probleminha

4 Compreendemos a constituição do conhecimento na perspectiva fenomenológica e para isso valer-nos-emos do apresentado em Bicudo e Afonso da Silva (2018) que expõem de maneira clara as diferenças epistemológicas dos termos constituição e produção do conhecimento. De acordo com eles, a constituição do conhecimento é um movimento em que pelo entrelaçamento dos sentidos experienciados no corpo-próprio ou corpo-encarnado, pelos diferentes órgãos, como audição, tato, visão, paladar, olfato e um sexto, cinestesia (movimento sentido), que vão se amalgamando e possibilitando a percepção de um objeto e sua forma em termos de figura e fundo, o qual se presentifica no fluxo da consciência. A produção do conhecimento está associada à intersubjetividade e dá-se por meio de experiências subjetivas de cada indivíduo que são expressas pela linguagem e articuladas de modo inteligível para os sujeitos da comunidade que partilham das compreensões explicitadas. Esses significados vão sendo expressos para a comunidade e à medida que são aceitos e aplicados vão sendo mantidos e repetidos nas atividades realizadas pelos diferentes membros da comunidade. Assim, os diferentes sujeitos realizando as atividades, repetindo os modos de produção e mantendo os significados vão produzindo o conhecimento histórico sócio cultural da comunidade e em grupos nela formados.
} 
formalizada é perfeitamente precisa. ${ }^{5}$ Conforme se sabe essa noção de prova é central em lógica matemática e levou a importante avanços na compreensão de muitas questões fundamentais e metamatemáticas que permitiram acreditar que todas as teorias matemáticas atuais podem ser formalizadas na teoria dos conjuntos de Zermelo-Fraenkel com o axioma da escolha (ZFC) que é uma teoria de estruturas de lógica de primeira ordem.

Em geral, na linguagem comum entre matemáticos e estudantes dessa ciência, falamos provar teoremas. Porém, vemos como mais apropriado falar em demonstração ${ }^{6}$, pois, provas formais datam pós os trabalhos de Gottlob Frege (18481925), referindo à segunda metade do século XIX e aparecem quase exclusivamente em textos de Lógica Matemática ou de Ciência da Computação. Nesse âmbito, o foco é o discurso matemático que envolve demonstrações pela justificativa principal da tentativa de tornar compreensível e convencer ao leitor da veracidade do resultado.

Assim,

Uma demonstração em S (um sistema formal, pensado como uma linguagem, um conjunto de sinais e um conjunto de regras para a manipulação de sinais) é uma sequência finita não vazia de sentenças de $\mathrm{S}$ tal que cada uma delas é um axioma ou uma consequência imediata, por regras de inferência admitidas em $\mathrm{S}$, de suas sentenças anteriores na sequência. Um teorema de $\mathrm{S}$ é uma sentença $\mathrm{A}$ de $\mathrm{S}$ tal que existe uma demonstração em $\mathrm{S}$ onde $\mathrm{A}$ é a última sentença da sequência. (Garnica, 2010, p. 70).

Dado o entendimento explicitado a respeito de demonstração matemática, focamos, agora, o que diferencia, por exemplo, duas provas do mesmo teorema, ou seja, o que faz a segunda prova não ser exatamente igual à primeira e ser então aceita como uma demonstração alternativa.

Buscando clarificar questões pertinentes às diferenças, consideramos duas demonstrações alternativas. Colocamos em destaque os argumentos articulados e expostos em ambas.

Dawson (2015) questiona se uma prova baseada em hipóteses mais fracas ou menos fracas deve/pode ser considerada como constituindo o mesmo teorema, um teorema mais fraco ou um teorema mais forte. Sobre isso ele argumenta:

Suponha, por exemplo, que um teorema $\mathrm{T}$ seja primeiramente provado a partir de um conjunto $\mathrm{H}$ de hipóteses, mas que mais tarde uma prova de T que emprega como hipóteses apenas algum subconjunto $\mathrm{P}$ de $\mathrm{H}$ seja obtida. Assim, tem-se duas provas diferentes de $\mathrm{T}$, ou tem-se provado no primeiro caso a implicação $\mathrm{H} \rightarrow \mathrm{T}$ (onde $\wedge \mathrm{H}$ indica a conjunção ${ }^{7}$ de todas as hipóteses em $\mathrm{H}$ ) e, no segundo caso, a implicação $\wedge \mathrm{P} \rightarrow \mathrm{T}$ (um resultado mais forte)? (Dawson, 2015, p. 2, tradução nossa).

\section{E ele próprio explica que}

Formalmente, a diferença entre duas demonstrações que utilizaram como argumentos o conjunto de hipóteses e um subconjunto é meramente uma questão de perspectiva, uma vez que o teorema da dedução para a lógica de primeira ordem estabelece a equivalência de uma AT e $\vdash \wedge \mathrm{A}$ T para qualquer conjunto A de axiomas não-lógicos. (Dawson, 2015, p. 2, tradução nossa ${ }^{1.8}$

Nesse caso, entendemos, então, que as duas demonstrações assumem perspectivas diferentes, porém, são vistas como equivalentes.

Por sua vez, provas que assumem premissas baseadas em conjuntos logicamente não equivalentes devem ser consideradas diferentes, visto que a totalidade do contexto em que uma prova é validada não é o mesmo em que a outra o é.

Pode ocorrer que, para atender públicos e objetivos distintos, matemáticos se empenhem na construção de provas alternativas em Matemática. Dawson (2015) argumenta que as provas podem ser diferentes: i) pode ser direta ou construtiva e empregar uma técnica particular (indução matemática, por exemplo, ou uma determinada regra de inferência) e isso a diferencia de uma que não utiliza essas regras; ii) uma pode dar informação mais completa do que a outra; iii) pode produzir diferentes consequências de modo que um resultado empregado como lema em uma demonstração de um teorema pode aparecer como um corolário desse teorema se for provado por outros meios; iv) uma prova pode ser válida num contexto mais amplo do que outra e pode ser compreensível para um público específico, enquanto para outro não; v) pode diferir na forma como noções primitivas são organizadas nos diferentes níveis dos conceitos, refletindo uma interação entre a prova e definições utilizadas.

A diferença entre provas distintas é, muitas vezes, uma questão que envolve o julgamento a respeito de serem elas essencialmente diferentes entre si ou tão somente uma simples variante, por serem mais simples ou por terem graus de pureza

5 The notion of what constitutes a proof in a formalized theory is perfectly precise: It is a finite sequence of well-formed formulas, the last of which is the statement to be proved and each of which is either an axiom, a hypothesis, or the result of applying one of a specified list of rules of inference to previous formulas of the sequence. That notion of proof, central to mathematical logic, has led to important advances in the understanding of many foundational and metamathematical issues, and it is widely believed that all current mathematical theories can be formalized within the framework of first-order Zermelo-Fraenkel set theory. Nevertheless, formal proofs are not the focus of the present inquiry (Dawson, 20150

6 Consideramos necessário observar que nessa página há duas notações diferentes para os mesmos objetos. Aqui está apresentada a diferença entre prova formal (prova) e demonstração, de acordo com o uso nas línguas Portuguesa, Francesa eAlemã. Logo abaixo na citação de Garnica é seguida a notação usual Inglesa e Espanhola que fala em prova (como demonstração) e prova formal. Na comunidade matemática convive-se diariamente com as duas notações, porém, como o artigo visa um público mais amplo vale a pena citar o fato.

7 Na citação de Dawson, o termo conjunção é tomado no sentido que a conjunção das fórmulas A e B é a fórmula AeB, em geral denotada A^B , é a generalização da conjunção para um conjunto eventualmente infinito de fórmulas.

8 Formally, the distinction is merely a matter of perspective, since the Deduction Theorem for first-order logic establishes the equivalence of AT e + $\wedge \mathrm{A}$ T) $\mathrm{T}$ for any set A of non-logical axioms. 


\section{diferentes. ${ }^{9}$}

Vários são os motivos, segundo Dawson (2015), que impulsionam a busca por novas provas de resultados estabelecidos anteriormente. Ele cita, entre alguns: corrigir os erros e preencher as lacunas percebidas em argumentos anteriores; evitar realizar provas que envolvessem o emprego de resultados ainda não estivessem claros. Uma evidencia desse motivo pode ser que Euclides retardou o quanto pode trabalhar com o quinto postulado no Livro I e hoje é consenso que foi uma atitude deliberada pois ele tinha dúvida se tal resultado poderia ser provado, pois, diferente dos outros quatro postulados, ele não podia ser empiricamente validado e sua escrita tinha uma condicional; as tentativas persistentes, antes das obras de János Bolyai (1802-1860) e Nicholai Lobachevsky (1792-1856), de deduzir o postulado das paralelas dos outros axiomas da geometria euclidiana, buscando eliminar hipóteses supérfluas ou controversas; a prova da completude de Leon Henkin em 1947 para a linguagem de primeira ordem que é válida tanto para linguagens finitas como para infinitas, a qual aumentou o alcance da validade do teorema; as provas dos matemáticos dos séculos XVI e XVII, opondo-se à prova de Arquimedes pelo método de exaustão, buscando realizar provas mais perspicazes e visando terminar com as objeções daquela demonstração.

Dawson (2015) explica que o aspecto exemplificado pelo desejo de evitar o emprego de argumentos de superposição em provas euclidianas visa realizar a demonstração utilizando método puro. Essa preocupação é diferente da preocupação com o rigor em que uma prova pode ser considerada deficiente. A antiga exigência grega de que construções geométricas sejam realizadas somente com compasso e régua sem numeração pode ser tomada como um dos motivos que leva à busca pela pureza do método. Outros casos seriam, por exemplo, o objetivo de encontrar uma prova elementar do teorema dos números primos, ou de encontrar uma prova para a consistência da aritmética formalizada de Peano, utilizando métodos formalizáveis no âmbito da própria teoria.

Além de uma busca por utilizar métodos puros nas demonstrações, notamos também na articulação de Dawson (2015) que simplicidade em uma demonstração é um critério estético que tem sido perseguido. Entretanto, o julgamento sobre se uma prova é mais simples do que outra tem até agora sido feito principalmente com base em critérios informais, uma vez que o conceito de simplicidade não é formalmente preciso.

Nos escritos de David Hilbert, acessados após a morte dele, localizou-se o registro daquele que seria o $24^{\circ}$ problema na lista que elaborou para a apresentação em seu famoso discurso no Segundo Congresso Internacional de Matemática de 1900. A nota dizia da necessidade de se ter claro os critérios de simplicidade de uma prova, com o entendimento de que sob um dado conjunto de condições, pode haver uma prova mais simples. A respeito de simplicidade de provas, uma prova pode ser mais simples do que outra, em vários aspectos: pode ser significativamente mais curta, pode envolver menos pré-requisitos conceituais, pode reduzir a extensão de cálculos a serem realizados ou reduzir o número de casos a ser considerados, por exemplo.

Entendendo que a Matemática é uma realização humana, a habilidade de demonstrar teoremas pode ser desenvolvida por tentativas de provar resultados dela própria. Nesse movimento, pode-se conceber um argumento não dado anteriormente, pois as pessoas pensam de maneiras diversas. Em alguns casos, os autores das demonstrações podem não estar cientes de outras provas que foram realizadas por diferentes pessoas e, assim, novos resultados podem ser construídos em diferentes culturas e de maneira independente por indivíduos que se utilizam de diferentes argumentos.

\section{As Demonstrações Alternativas e as Re-Demonstrações como Produção do Conhecimento Matemático}

Quando nos referirmos às demonstrações alternativas estamos considerando as demonstrações diferentes do mesmo resultado. Quando nos referimos à re-demonstrar significa teoremas cujas demonstrações são conhecidas bem como a estrutura delas. Uma vez conhecidas a estrutura e a mensagem estabelecida pelo teorema, realiza-se um exercício de criação de outra(s) sequência(s) de fórmula que expressam o mesmo resultado. Esse segundo tipo, comum na graduação em matemática, diz do debruçar-se sobre teoremas estudandoos, refazendo a demonstração e buscando compreender as ideias e os argumentos presentes nela e/ou realizando outra demonstração do mesmo resultado. Esse exercício de produção matemática viabiliza a apropriação do ferramental, dos resultados disponíveis e conhecidos no âmbito daquela teoria e das aplicações do teorema na resolução de problemas na própria ou em outras teorias.

Nos grupos de pesquisa, os matemáticos estão-juntoaos-outros se ocupando de estudos em torno de um projeto de pesquisa, tidos como importante para todos, cujo tema investigativo abrange o interesse individual e coletivo de seus membros. Isso possibilita a organização da vida comum nessa comunidade. Os profissionais matemáticos convivem e se empenham em familiarizarem-se com o método de produção da

9 A preocupação com a pureza do método implica uma restrição aos meios de prova. Quando um determinado teorema de uma teoria é provado apenas pelos meios daquela teoria pode-se afirmar que a prova é metodologicamente pura. Por exemplo, o teorema de Desargues no plano (assim enunciado: se dois triângulos no mesmo plano são orientados de modo que as linhas que unem os correspondentes vértices são simultâneas, os lados correspondentes, se estendidos como linhas, cruzam em três pontos colineares) é um teorema da geometria plana e da geometria projetiva também e, em nome da pureza, pode-se buscar uma prova puramente plana ou somente por meios projetivos.

10 Há um solo intersubjetivo constituído pela intropatia e pela linguagem quando os diferentes membros se dedicam à comunidade, se veem como iguais e podem se compreender e compreender seus discursos. Ainda que realizem trabalhos em frentes diferentes, no âmbito do grupo eles mantém o núcleo da comunidade do qual emerge a característica do grupo e garante a duração, sustentando a vida comunitária dos membros. 
ciência e com os instrumentos de que se valem para convencer a si próprio e aos demais ${ }^{10}$ quanto à veracidade e correção de demonstrações. Isso exige o compartilhamento de regras e de conceitos matemática, bem como do conceito vigente de rigor. $\mathrm{Na}$ comunidade aqui explicitada, os seus membros também assumem responsabilidades mútuas na atualização do modo de essa comunidade ser e permanecem solidários.

Quanto às demonstrações alternativas, destacando a vida em comunidade, cada membro tem a liberdade de elaborá-las, desde que se valham das ideias e argumentos que respeitem o projeto conjunto, ou seja, as concepções e as ferramentas compartilhadas. Porém, a demonstração alternativa deve ser convincente para a comunidade e também para o membro que a elaborou.

As produções e a divulgação de provas alternativas têm sido eventos recorrentes e proeminentes na comunidade matemática. Os matemáticos de diferentes lugares demonstram novamente teoremas que já foram provados e o fazem diferenciando, principalmente, os meios utilizados e os resultados encadeados na argumentação lógica. Isso nos permite entender demonstrações alternativas como produções humanas repletas de aspectos subjetivos dos sujeitos que se dispõem a realizá-las juntamente com ideias veiculadas em diferentes comunidades de matemáticos, as quais integram a comunidade mundial de matemáticos.

As demonstrações alternativas são diferentes principalmente pelos resultados que são articulados na argumentação muitas vezes advindos de teorias diferentes.

Re-demonstrar ou refazer demonstrações possibilita, sobretudo, a compreensão das ideias envolvidas na demonstração original e a experimentação de outras vias que conduzem ao resultado no âmbito da teoria que circunscreve o resultado. O redemonstrar diferencia-se do refazer a demonstração. O refazer diz de quando a demonstração é estudada e reapresentada revelando detalhes que estavam ocultos na argumentação.O re-demonstrar é quando a demonstração é refeita e ainda mais, quando há a expressão de individualidades que se manifestam nos diferentes estilos de escrita, na utilização de outros diferentes axiomas e teoremas utilizados na argumentação lógica focada, ou no arranjo desses resultados na sequência de fórmulas que constitui a última linha da sequência, ou seja, o teorema.

A obra Why Prove it Again?: Alternative Proofs in Mathematical Practice de Dawson (2015) permitiu-nos entender como e porque matemáticos produzem demonstrações alternativas, desvelando essa atividade matemática, as escolhas realizadas e a energia vital despendida direcionada para o re-demonstrar. Este autor contribui com nossas reflexões na medida em que ele elucida que provas alternativas podem surgir simplesmente como expressões dos padrões individuais de pensamento, talvez refletindo preferências ou a criação de itinerários particulares. Podem surgir sem a pretensão de corrigir erros ou de eliminar hipóteses supérfluas; sem o objetivo de ser mais acessível à determinado público ou de aumentar o alcance do resultado na própria Matemática.

As provas alternativas, quaisquer que sejam as motivações que as produziram, tomam parte de uma rede de demonstrações que pode aumentar a confiança geral nos resultados matemáticos, conforme nos revela Dawson (2015). Em relação aos matemáticos que produzem demonstrações alternativas pelo desafio de fazê-lo, Dawson os compara à alpinistas de montanhas e sugere que são levados a resolver os problemas pela mesma razão que alpinistas são levados a escalar montanhas, ou seja, pelo estímulo frente ao desafio, uma vez que estão ao pé da montanha e interessam-se por trilharem a rota até o topo, valendo-se de seus próprios meios, mesmo sabendo que outro (ou outros) já realizou (realizaram) a trilha e foi (foram) reconhecido(s) entre os pares na comunidade por seu(s) feito(s).

Esse autor expõe que há matemáticos que consideram suficiente régua e compasso numa demonstração, por exemplo. A nova prova desenvolvida pode exibir determinada economia de meios ou pode ser considerada mais inteligente, no sentido de apresentar em sua articulação intuições inusitadas. Dawson (2015, p.11) põe em relevo que

Para além das razões específicas para fornecer provas alternativas, há também uma que é de mais abrangente propósito, muitas vezes esquecido, que várias provas, analogamente, servem ao papel de confirmação nas ciências naturais. Ou seja, assim como um acordo entre os resultados de diferentes experiências aumenta a credibilidade em hipóteses científicas (e assim também nas teorias maiores dentro do qual as hipóteses são emolduradas), diferentes provas de teoremas reforçam a confiança não apenas nos resultados particulares assim provados, mas na estrutura global e na coerência da própria matemática. (Tradução nossa).

Nessa visão, as provas alternativas contribuem para aumentar a confiança em relação ao resultado que foi provado, tornando-o cada vez mais inquestionavelmente válido, ou seja, convincente para a comunidade matemática. Elas fortalecem o conhecimento matemático produzido histórico-socialmente, uma vez que, a cada nova demonstração vivências subjetivas contribuem com modos diferentes de ver e compreender o teorema e sua respectiva prova e, desse modo, vão diluindo eventuais dúvidas sobre a confiabilidade da demonstração já existente ou sobre a confiabilidade nos caminhos já percorridos.

A realização de provas ou demonstrações ou redemonstrações sobre a existência de um objeto matemático é uma prática argumentativa que envolve adaptações ao público a que se destina. Os pressupostos explicitados, em maior ou menor medida, referem-se ao grau de detalhamento que pode ser acompanhado pela comunidade a fim de convencer seus membros a respeito da correção dos resultados. Assim sendo, podemos considerar que o grau de compreensão de uma demonstração varia conforme a familiaridade do público com o ferramental com o qual o matemático trabalhou. Isso diz da capacidade de inspecionar o processo do modo mais detalhado possível, perscrutando os conceitos e métodos matemáticos envolvidos. 
Na esteira dessa argumentação sobre justificativas para a existência de provas alternativas de teoremas, Halmos (1985) em sua obra How to be a mathematician?, expõe que criação e publicação de resultados é uma parte comum no trabalho de um matemático profissional e de um professor de matemática de Ensino Superior. O matemático, sendo pessoa humana que, na rede de contatos com pessoas de sua comunidade, necessita expor suas produções e manter-se ativo em seu ambiente de trabalho e de pesquisa.

Disso, compreendemos que a atividade profissional do matemático envolve a criação de provas alternativas de resultados previamente estabelecidos e a divulgação desses resultados, bem como, no caso daqueles que ensinam em cursos superiores, formando matemáticos ou professores de matemática abrange a atividade de ensino dessa ciência. Entendemos, ainda, que provas alternativas podem responder algum intento pessoal de compreensão, como é o caso da apresentada em Cifuentes (2013) ${ }^{11}$, ou pode ser a expressão de alguma compreensão pessoal de um tema de modo diferente daquele presente nas demonstrações conhecidas.

Provas alternativas também podem ser criadas com objetivos didáticos e pedagógicos. Realizadas por autores de livros didáticos e por alunos de diferentes graus de ensino, as provas alternativas se revelam como uma prática e importante para a produção da matemática. Essa prática se dá em contextos de ensino e aprendizagem de Matemática. Conforme Garnica (2002, p.1), “a Educação Matemática, na perspectiva de área de conhecimento teórico-prática é movimento que se institui no instante em que algo a que chamamos Matemática ocorre". Nessa ocasião focamos as demonstrações alternativas, compreendendo-as como produção de Matemática em estado nascente, uma vez que abrem campo s de atividades de aprendizagem de ferramental específico, de encadeamentos rigorosos de raciocínios, de compreensão de linguagem específica da matemática, de esforço para compreender os passos dados pelo autor do texto ao demonstrar a prova que está sendo trabalhada, abrindo-se a intuições possíveis.

Para além dos interesses desafiadores da realização da nova demonstração, o produto desse fazer fortalece a comunidade matemática ao apresentar expressões de subjetividades tecidas. A nova demonstração possibilita que se compreenda aspectos do "funcionamento do discurso matemático e o modo como são engendradas as concepções que permeiam a sala de aula de Matemática sendo, por isso, tema importante à Educação Matemática" (Garnica, 2002, p.5).

Nas palavras de Dawson (2015, p.12), como já exposto, as demonstrações alternativas conduzem à confiança

A confiança em resultados matemáticos é baseada mais sobre a multiplicidade e variedade das deduções que levam a eles, do que sobre a conclusividade de qualquer um desses raciocínios dedutivos. O raciocínio matemático não é uma cadeia, não mais forte do que seu elo mais fraco, mas um cabo, cujas fibras, embora sempre tão esbeltas, são numerosos e intimamente conectadas.

Re-demonstrar teoremas não os torna mais verdadeiros. É sabido que a literatura matemática é permanente, no sentido de um teorema demonstrado como verdadeiro não poder ser demonstrado como falso em algum outro momento considerando as mesmas condições circunscritas ao seu próprio enunciado. Ao compreendermos de modo mais aprofundado as atividades presente na re-demonstração de teoremas, entendemos que a atividade do matemático vai além do que afirmamos em Batistela, Barbariz \& Lazari (2016), pois na comunidade matemática tão importante quanto demonstrar é re-demonstrar e o trabalho do matemático profissional inclui além de definir seus conceitos e demonstrar as propriedades desses conceitos também criar provas alternativas de resultados já demonstrados. Seja por desejo pessoal como desafio, como exercício de reflexão ou para fins didáticos; seja sem a intenção desse fim por desvios de percurso em algum trabalho; seja com objetivos de refino do método, de economia de argumentos. Demonstrações alternativas é um tema para o qual muitos matemáticos direcionam suas energias.

\section{Re-Demonstrações Produzidas Acidentalmente}

Temos clareza sobre a intenção consciente de matemáticos ao se colocarem na lida de realizarem re-demonstrações dos teoremas. Contudo, também sabemos que muitas são as redemonstrações produzidas acidentalmente, as quais podem surgir na busca por demonstrar a existência de outro objeto matemático.

A respeito de teoremas produzidos acidentalmente, um desses episódios pode ser acompanhado em Henkin (1996) na obra The discovery of my Completeness Proofs. Este autor expõe sua experiência vivenciada no curso de doutorado que o conduziu à demonstração alternativa do teorema da completude da lógica de primeira ordem. Este resultado tinha sido provado dezoito anos antes por Kurt Gödel (1906-1978) ${ }^{12}$, em 1929. O relato de Henkin (1996) tornou possível compreender o movimento da constituição e da produção matemática ao trazer as ideias que foi entendendo de modo claro e as evidências que o fizeram ver de mais maneira mais clara o teorema da completude, durante o processo de demonstração alternativa desse teorema. Essa compreensão possibilitou, conforme se entendeu mais tarde, o desenvolvimento inicial da teoria dos modelos. Ao apresentar o processo realizado, Henkin (1996), vale-se de uma metáfora que diz de uma "caixa preta" em que se dão as etapas de uma demonstração. Ele se dá conta de que o resultado de saída, o teorema da completude, a demonstração de Gödel e a dele próprio, nos dois casos, são equivalentes,

11 Trata-se de um texto (que não foi publicado) intitulado "A verdade matemática, mais que um objeto de conhecimento, é um objeto de contemplação" escrito, segundo o próprio autor afirmou verbalmente, como um exercício de compreensão do que na opinião do autor são os dois resultados mais profundos da Matemática, o teorema de indefinibilidade de Tarski e o teorema da incompletude de Gödel.

12 O teorema da completude da lógica de predicados ou teorema da completude da lógica de primeira ordem foi apresentado como resultado do doutorado de Gödel em 1929. Dois anos depois, em 1931, Gödel provou o teorema da incompletude da aritmética básica de Peano. 
embora os teoremas tenham sido produzidos por entradas diferentes, ou seja, por argumentos diferentes.

Esse autor descreve uma série de vivências que possibilitaram a ele a organização daquelas ideias de entrada. Afirma que percebe aspectos que influenciaram as escolhas e que the possibilitaram chegar à demonstração alternativa. Ao apresentar suas ideias, vai clarificando o modo como ele desenvolveu essa demonstração e evidenciando que as duas demonstrações focadas são distintas, embora tenham o mesmo resultado na saída. Esclarece compreender que as ideias de entrada de uma demonstração são predileções pessoais advindas de estudos e de trabalhos realizados anteriormente ou de produções por esforço partindo de leituras independentes ou palestras assistidas. Relata que produziu a demonstração alternativa no doutorado, valendo-se dos conhecimentos que foi articulando durante seus estudos. Entendemos que toda essa trajetória se dá estando na comunidade matemática com-os-matemáticos e estudiosos dessa ciência, comunidade essa da qual ele participa como pessoa em sua totalidade física, psíquica e espiritual. ${ }^{13}$

É raro encontrarmos textos de matemáticos ocidentais que explicitam as escolhas realizadas em suas demonstrações, mostrando os caminhos trilhados, tal como faz Henkin (1996). Este autor apresenta o processo de que ele realizou ao descobrir de forma acidental o resultado destacando ideias que foram abandonadas devido a entendimentos que ocorriam no decorrer do trabalho apresentado. Afirma que seguia os ensinamentos e escritos de seu professor Alonzo Church que dava grande ênfase ao caráter construtivo da lógica matemática. Henkin (1996, p.128) argumenta:

Uma descoberta matemática é uma idéia, ou um complexo de idéias, que têm sido encontradas e estabelecidas em certas circunstâncias. O processo de descoberta consiste em selecionar certas idéias de entrada e de alguma forma combinar e transformá-las para produzir as novas ideias de saída [...]. Para descrever essa descoberta é preciso explicar o que ocorre no interior da caixa, ou seja, como as saídas foram obtidas a partir das entradas.

Fica claro para nós que a demonstração alternativa produzida por Henkin para o teorema da completude do cálculo de predicados foi um resultado casual que tem relação direta com os objetos de entrada que ele articulou e que não foi um resultado que objetivava ser uma demonstração alternativa do teorema da completude da lógica de predicados de primeira ordem. Compreendemos que esse relato de Henkin (1996) revela a conexão profunda que há entre os axiomas das diferentes teorias. Como não há demonstração sem haver uma teorização, o fato de Henkin (1996) chegar casualmente a uma demonstração alternativa do teorema da completude da lógica de primeira ordem evidencia que ali há uma teorização na qual vale o teorema da completude da lógica. De fato parecer assim ser, pois o próprio Henkin (1996) conta que esta descoberta contribuiu para o desenvolvimento inicial da teoria dos modelos.

A produção matemática e teorias matemáticas estão imbricadas umas nas outras e não há demonstrações sem haver uma teorização e todas as demonstrações são circunscritas numa teoria. As demonstrações são as que vão validar uma dada teoria que é construída a partir de uma problematização que não tinha uma resposta na teoria vigente.

As ideias de entrada que Henkin (1996) admite ter usado advém da intensidade da participação dele na comunidade matemática que abarca o grupo de pesquisa do qual ele participava e que era liderado por Alonzo Church (1903 - 1995).

\section{A Importância de e por que Re-Demonstrar Teoremas em Cursos de Formação Inicial de Matemáticos e Professores de Matemática}

Este estudo buscou compreender os motivos que impelem matemáticos a realizar demonstrações alternativas. Compreendemos que realizar demonstrações, demonstrações alternativas ou re-demonstrações são práticas presentes na constituição e na produção de conhecimento matemático. Os motivos e as necessidades que envolvem a realização de demonstrações alternativas na prática matemática profissional nos ajudam a refletir sobre a coerência e a relevância do trabalho com elaboração de re-demonstrações na graduação.

A prática de matemáticos profissionais na criação de demonstrações alternativas evidencia os diferentes pontos de vista e concepções da matemática e de rigor vigentes na comunidade matemática em que são respeitadas as diferentes manifestações e incentivados os diferentes estilos de escrita. Uma vez que essas ações fazem parte da natureza do trabalho de um matemático profissional, entendemos que realizálas também com estudantes de níveis diferentes de ensino é importante para a aprendizagem a respeito da própria lógica da produção e, ao mesmo tempo, para criar uma atmosfera de ensino e de aprendizagem que sensibilize os sujeitos envolvidos para perceberem intuições que acabaram sendo explicitadas e articuladas nas demonstrações.

Polya (1964) quando expõe sua compreensão sobre porque resolver o mesmo problema de uma nova maneira aproxima-se do que é afirmado por Dawson (2015) a respeito das razões explícitas pelas quais os matemáticos têm realizado provas alternativas de resultados conhecidos. Polya (1964, p.61-62) afirma:

Mesmo que tenhamos êxito em encontrar uma solução satisfatória, nós ainda podemos estar interessados em encontrar outra solução. Desejamos nos convencer da validade de um resultado teórico por duas diferentes derivações como nós desejamos para perceber um objeto material através

13 Apoiados em Ales Bello (2015), explicitamos: Em fenomenologia toda pessoa humana tem corpo, psique e espírito que são entendidos como capacidades humanas que podemos e devemos desenvolver. Por exemplo, o corpo permite-nos o movimento; a psique tem os estados vitais que são e pelo espírito podemos realizar atividades de aceitar ou transformar a realidade. O sujeito humano diferencia-se dos demais seres vivos e dos minerais porque uma pessoa tem a possibilidade de captar e conhecer e assim compreender o outro. Embora toda pessoa tenha esses três aspectos, cada uma distingue-se das outras pelo núcleo identitário que é um elemento último e profundo que diz respeito aquilo que diz respeito às características absolutamente singulares. A morte dá-se quando essas capacidades se enfraquecem. 
de dois sentidos diferentes. Tendo encontrado uma prova, queremos encontrar uma outra prova de como queremos tocar um objeto depois de tê-lo já visto.

Compreendemos que a produção de re-demonstrações é, para alunos de cursos universitários iniciais de matemática, ocasião oportuna e frutífera de trabalhar com o objeto matemático possibilitando que ele seja abordado de diversas maneiras e por diversos estudantes, semelhantemente ao trabalho demonstrações alternativas na prática profissional de matemáticos. A referência a George Polya nos remete aos problemas matemáticos e ao processo antevisto e organizado de ensino de matemática por meio da metodologia da resolução de problemas. Compreendemos que não é todo problema que pode ser entendido como oportunidade de produção da matemática semelhante à que pode ocorrer na criação de uma demonstração alternativa. Sabemos que somente os que exigem que os sujeitos envolvidos entrelacem, no processo de resolução, certos atos de percepção e de cognição, satisfazendo, então, as condições de ser um problema característico de um ambiente de resolução de problemas.

Não distinguimos o fazer individual do coletivo. Tomamos nesse momento o processo de elaboração de re-demonstrações na graduação em matemática quando do trabalho em grupo na sala de aula. Nessa perspectiva tem-se estudantes estandocom-outros, sendo esses outros o(s) colega(s) ou o professor. Esse estar-com-o-outro revela-se nos modos pelos quais essas pessoas estão juntas, nos diálogos estabelecidos, nas atitudes e manifestações de concordâncias, discordâncias, entendimentos, dúvidas, nos completamentos das demonstrações realizadas conjuntamente na lousa, elaboração de questões que não estavam diretamente relacionadas ao que estava sendo trabalhado, mas ao ensino na graduação.

A produção da Matemática enquanto ciência ocidental é exposta em teorias formalizadas por meio de demonstrações e por aplicações práticas. Tomando-se a demonstração original de um teorema e as demonstrações alternativas dele, faz-se importante destacar que as demonstrações alternativas explicitam o caráter dinâmico da produção matemática e das verdades dessa ciência, as quais são constituídas em um dado momento histórico em uma comunidade e, portanto, não são absolutas. As concepções de Matemática de cada época geram os questionamentos que os matemáticos buscam responder. Esses questionamentos variam em momentos históricos diferentes e perpassam a busca de rigor matemático. A nosso ver, as demonstrações alternativas correspondem a uma contribuição original, pois são conhecimentos constituídos na vivência que passam a fazer parte dos conhecimentos da comunidade matemática quando divulgados e expressos na linguagem na intersubjetividade. Entendemos, portanto, que trabalhar com re-demonstrações e demonstrações alternativas é uma atividade importante a ser realizada com alunos em formação no âmbito da matemática.

As demonstrações são produzidas e seguem o protocolo que articula os pressupostos apresentando-os dedutivamente. Contudo é sabido que o pensamento dedutivo nem sempre prevalece no trabalho que envolve a elaboração de uma demonstração, muito embora, ingenuamente, seja assim compreendido.

\section{Conclusão}

Muitas vezes a evidência do resultado precede a sequência de linhas, dos itinerários, que estabelecem o teorema. Outras vezes a intuição do resultado é frustrada, como pode-se notar no episódio da prova do teorema da incompletude de Gödel que, em relação à prova da consistência da aritmética de Peano, estabelece a impossibilidade dessa prova por métodos formalizáveis no âmbito da própria aritmética. O projeto do formalismo de Hilbert trazia a crença de que a realização dessa prova era uma questão de tempo e empenho dos matemáticos e toda produção matemática desse grupo de matemáticos assentava-se sobre a consistência da aritmética. Isso provocou um abalo no projeto formalista ao mesmo tempo em que significou um revigoramento para as questões dos fundamentos da Matemática. Entre outras coisas, provocou uma mudança na concepção de Matemática e transmitiu uma ideia revigorante ao incluir na equação da produção do conhecimento matemático o elemento que afirma que a natureza da matemática não permite se circunscrever, ou seja, ter os limites de suas teorias bem determinados e circunscritos a elas.

\section{Referências}

Ales Bello, A. (2006). Introdução à Fenomenologia. Bauru: EdUSC.

Ales Bello, A. (2015). Pessoa e comunidade. Bauru: Artesã.

Batistela, R.F., Barbariz, T.A.M. \& Lazari, H. (2016). Um estudo sobre demonstração matemática por/com computador. Revemat, 11, 204-215.

Bicudo, M.A.V. \& Afonso da Silva, A. (2018). Análise de descrições de vivências em situação de constituição de conhecimento. In: A.P. Costa. M.C. Sánchez-Gómez, \& M.V.M. Cilleros A prática na Investigação Qualitativa: exemplos de estudos (158-178). Aveiro: Edicão Ludomedia.

Dawson, J. W. (2015). Why prove it again?: alternative proofs in mathematical practice. Basel: Birkhäuser.

Garnica, A. V. M. (2002). As demonstrações em Educação Matemática: um ensaio. Bolema, 15 (18), 91-99.

Garnica, A.V.M. (2010). Da literatura sobre a prova rigorosa em Educação Matemática: um levantamento. In A. P. P. Baumann . Maria em Forma/Ação (69-100). Rio Claro: IGCE.

Halmos, P. R. (1985). I want to be a mathematician: an automathography. New York: Springer-Verlag New York.

Henkin, L. (1996). The discovery of my completeness proofs. The Bulletin of Symbolic Logic, 2 (2), 127-158.

Nagel, E. \& Newman, J. R. (1973). A Prova de Gödel. São Paulo: Perspectiva.

Polya, G. (1964). How to solve it: a new aspect of mathematical method. New Jersey: Princeton University Press.

Viola dos Santos, J. R., \& Lins, R. C. (2008). Movimentos de Teorizações em Educação Matemática. Boletim de Educação Matemática, 30 (55), 325-367. 